\title{
First Nigerian Bioinformatics Conference (FNBC): Towards a dynamic bioinformatics community
}

\author{
ThankGod E. Ebenezer ${ }^{1+}$, Itunuoluwa Isewon², Elijah Kolawole Oladipo ${ }^{3}$, Olaitan I.
} Awe $^{4}$, Marion Adebiyi ${ }^{2,5}$, Yvonne Ajamma², Nusrah Afolabi Balogun ${ }^{6}$, Emuejevoke T. Toye $^{7}$, Deborah E. Fasesan ${ }^{8}$, Zainab A. Kashim ${ }^{8}$, Olugbenga Oluwagbemi9,10, Jelili Oyelade $^{2}$, Faith Ogbole ${ }^{11}$, Benjamin Benthai ${ }^{12}$, ljeoma Asilebo ${ }^{7,13}$, Abati Abraham ${ }^{14}$, Tawakalt Olasumbo Oduwole ${ }^{15}$, Emmanuel Adamolekun ${ }^{16}$, Charles Oluwaseun Adetunji17, Umar Ahmad ${ }^{18}$, Abdulfatai Tijjani ${ }^{8}$, Callistus Akinleye ${ }^{19}$, Victor Chukwudi Osamor $^{2}$, Chika Onwuamah20, Olufemi Amoo ${ }^{21}$, Idowu A. Taiwo ${ }^{14}$, Bamidele Abiodun Iwalokun ${ }^{21}$, Chinwe Ekenna ${ }^{22}$, Babatunde Salako ${ }^{23,24}$, Ezekiel Adebiyi²,26,27, Oyekanmi Nashiru8, Segun Fatumo $8,28,29+$

\begin{abstract}
${ }^{1}$ Organisms and Ecosystems, Earlham Institute, Norwich Research Park Innovation Centre, Norwich NR4 7UZ, United Kingdom, 2Department of Computer and Information Sciences, Covenant University, P. M. B. 2013, Ota, Ogun State, Nigeria, ${ }^{3}$ Department of Microbiology, Adeleke University, P.M.B. 250, Ede, Osun State, Nigeria, ${ }^{4}$ Department of Computer Science, University of Ibadan, Ibadan, Oyo State, Nigeria, 5Department of Computer Science, Landmark University, Omu-Aran. Nigeria, ${ }^{6}$ Department of Chemical Sciences, Fountain University Osogbo, Osun State, Nigeria, ${ }^{7}$ Biologix Support Services Limited, Lagos, Nigeria, ${ }^{8}$ Center for Genomics Research and Innovation, National Biotechnology Development Agency, Abuja, Nigeria, ${ }^{9}$ Department of Mathematical Sciences, Stellenbosch University, Stellenbosch, 7602, Western Cape, South Africa, ${ }^{10}$ South African Center of Excellence for Epidemiological Modeling and Analysis (SACEMA), South Africa, ${ }^{11}$ Department of Chemical Sciences, University of Africa, Toru - Orua, Bayelsa State, Nigeria, ${ }^{12}$ Department of Biological Sciences, Nigerian Defence Academy Kaduna, P.M.B 2109, Kaduna State, Nigeria, ${ }^{13}$ Department of Pharmaceutical Microbiology and Biotechnology, University of Nigeria, Nsukka 410001, Enugu State, Nigeria, ${ }^{14}$ Department of Cell Biology and Genetics, University of Lagos, Akoka, Akoka Road, Lagos, Nigeria, ${ }^{15}$ Molecular Biology and Genetics Diversity Research Laboratory, Fountain University Osogbo, Osun State, Nigeria, ${ }^{16}$ Department of Medical Laboratory Science, Ladoke Akintola University of Technology, P.M.B. 4400, Osogbo Campus, Osun State, Nigeria, ${ }^{17}$ Department of Microbiology, Edo University lyamho, PMB 04, Auchi, Edo State, Nigeria, ${ }^{18}$ Department of Anatomy, Faculty of Medicine, Bauchi State University, PMB 65, Gadau, Nigeria, 19Department of Community Medicine, Osun State University, Osogbo, Nigeria, ${ }^{20}$ Centre for Human Virology and Genomics, Nigerian Institute of Medical Research (NIMR), PMB 2013, Lagos, Nigeria, ${ }^{21}$ Molecular Biology \& Biotechnology department, Nigerian Institute of Medical Research (NIMR), PMB 2013, Lagos, Nigeria, ${ }^{22}$ University at Albany, SUNY New York, USA ${ }^{23}$ College of Medicine, University of Ibadan, Ibadan P.M.B 3017, Oyo State, Nigeria, ${ }^{24}$ Nigerian Institute of Medical Research (NIMR), PMB 2013, Lagos, Nigeria, ${ }^{25}$ Covenant University Bioinformatics Research (CUBRe), Covenant University, Km 10 Idiroko Road, P.M.B. 1023 Ota, Ogun State, Nigeria, ${ }^{26}$ Covenant Applied Informatics and Communication African Centre of Excellence (CApIC-ACE), Covenant University, P.M.B. 1023 Ota, Ogun State, Nigeria, ${ }^{27}$ Division of Applied Bioinformatics, German Cancer Research Center (DKFZ), Im Neuenheimer Feld 280, 69120 Heidelberg, Germany, ${ }^{28}$ London School of Hygiene and Tropical Medicine, London, United Kingdom, ${ }^{29} \mathrm{Uganda}$ Medical Informatics Centre, MRC/UVRI and LSHTM Uganda Research Unit, Uganda.
\end{abstract}

+Corresponding authors: thankgod1980@yahoo.co.uk, segun.fatumo@gmail.com 


\section{Abstract}

The human genome project, which was completed in 2003, ushered in a new era of scientific applications in medicine and bioscience, and also enhanced the generation of high-throughput data which required laboratory and computational analytical approaches in fields known as genomics and bioinformatics respectively. Internationally, specific advances have been achieved which involved the formation and emergence of strong scientific communities to sustain these technological advancements. On the African continent and regionally, the Human Hereditary and Health in Africa (H3Africa), Biosciences eastern and central Africa - International Livestock Research Institute (BecA - ILRI) Hub, and the Alliance for Accelerated Crop Improvements in Africa (ACACIA), are helping to push some of these advances in human health, biosciences, and agriculture respectively. In Nigeria, we believe that significant advances have also been made by various groups since the human genome project was completed. However, a scientific gathering platform to sustainably enable scientists discuss and update these progresses remained elusive. In this article, we report the First Nigerian Bioinformatics Conference (FNBC) hosted by the Nigerian Bioinformatics and Genomics Network (NBGN) in collaboration with the Nigerian Institute of Medical Research (NIMR). The conference was held from 24th - 26th June, 2019, with the theme: "Bioinformatics in the era of genomics in Africa". Quantitatively, the conference recorded 195 online registered participants, and up to 186 actual participants; comprising of 8 keynote speakers, 6 invited speakers, 25 oral presenters, 83 poster presenters, and up to 73 non-presenting participants. Attendees with national (up to 179) and international (up to 16) affiliations also participated at the conference. Qualitatively, broad scope of bioinformatics, genomics and molecular biology presentations in biomedicine, health, and biosciences were featured at the conference. We discuss the conference structure and activities, lessons learned, and way forward for future bioinformatics conferences in Nigeria. We further discuss the relevance of the conference which presents an increased visibility for the Nigerian bioinformatics community, positions Nigeria as a dynamic community player within the African bioinformatics space, and provides a platform for national impact through the application and implementation of the benefits of bioinformatics.

Keywords: Bioinformatics, genomics, Nigeria, NBGN, conference, community, FNBC19 


\section{Introduction}

\section{Background to the conference}

In 1869 the first DNA was isolated (Dahm, 2005, Tan \& Yiap, 2009, for reviews), providing an enabling insight into the field of molecular biology. The discovery and description of the DNA helical structure in 1953 (Watson \& Crick, 1953; Pray, 2008) conceptualised 20th century molecular biology investigations. This was followed by the discovery of the genetic code in 1964 (Leder \& Nirenberg, 1964; Nirenberg \& Matthaei, 1961), and the launch and completion of the genomes of Homo sapiens (Berg, 2006; DeLisi, 2008; International Human Genome Sequencing Consortium, 2004; Watson \& Cook-Deegan, 1991), Caenorhabditis elegans (C. elegans Sequencing Consortium, 1998), and Saccharomyces cerevisiae (Goffeau et al., 1996). These projects further established the field of bioinformatics to assist with the analysis of high-throughput data being generated (Hagen, 2000; Weissenbach, 2016); this is not withstanding that bioinformatics has been in utility in the early 1960s - though was at its infancy (Gauthier, et al., 2018).

The corresponding advances in genomics and bioinformatics at the international level provided a new era of scientific applications and societal benefits; as could be seen from the assembling of scientists and policy makers in the conceptualisation of the Human Genome Project (Making \& Hanna, 1991) and the Earth BioGenome Project (Lewin et al., 2018) which aims to understand human health and the world's biodiversity respectively. In Africa, similar efforts have been directed to understand the African genetic populations, build scientific capacity of African scientists, and ensure that the African continent benefits from this genomic revolution (Adebamowo et al., 2018; Azeez et al., 2015; Bah, et al., 2018; Karikari, et al., 2015; Mulder et al., 2017; Mulder et al., 2017, 2016; Munung, et al., 2018; Shaffer et al., 2019). For instance, amongst others, several African human genetic and biodiversity population studies are being carried out by the Human Hereditary and Health in Africa (H3Africa) (Mulder et al., 2016), Biosciences eastern and central Africa - International Livestock Research Institute (BecA - ILRI) Hub (https://hub.africabiosciences.org), and the Alliance for Accelerated Crop Improvements in Africa (ACACIA) (Entfellner, 2018) respectively. At the centre of these project-based breakthroughs are bioinformatics and genomics 
scientific communities driving these agenda with regular convening platforms to constantly update on scientific findings, discoveries, and build collaborations (Mulder et al., 2017, 2016; DeLisi, 2008). Whilst these scientific updating methods and mechanisms exists internationally and continentally in the forms of conferences, one drawback is that many African countries, including Nigeria, lack the bioinformaticscommunity vibrancy and dynamism as being experienced at the continental level due to limited convening bioinformatics community populations; though South Africa, Kenya, Tunisia and Egypt may be outliers (Karikari, 2015).

\section{Justifications for the conference}

In Nigeria, bioinformatics has been nearly two decades old (Fatumo et al., 2014, Adeyemo, et al., 2018), though with lesser national community convening advances in comparison with countries in Eastern and Southern Africa (e.g Kenya and South Africa respectively). For instance, while Nigerians occupy significant positions and play prominent roles since the inception and running of H3Africa, H3ABioNet, and the African Society of Bioinformatics and Computational Biology (ASBCB) (Fatumo et al., 2014), the biennial African Bioinformatics conference is yet to be hosted in Nigeria; despite several ongoing bioinformatics works being carried out nationally and internationally by Nigerian bioinformaticians and genomicists (Karikari, 2015; Folarin et al., 2016, Oloniniyi et al., 2018; H3Africa Consortium et al., 2014; Ramsay \& Sankoh, 2016).

Similarly, as in many African countries, bioinformatics is yet to reach its full potential in Nigeria (Fatumo, et al., 2014, Adeyemo, et al., 2018) in areas of medical, biomedical, and bioscience applications. The attendant challenges forestalling these advances in some African countries, such as Nigeria, have recently been reported (Fatumo et al., 2014, Karikari, 2015, Mulder et al., 2017, Adeyemo, et al., 2018). Given the roles of Nigerians within the African bioinformatics space, a scientific conference to help address some of these challenges became very necessary; though it has proven elusive in the past several years. Such bioinformatics conference would help Nigerian bioinformaticians and genomicists answer some of these questions: Where are other Nigerian Bioinformatics investigators and what are their research interests? How do we bring the bioinformatics community together, and drive scientific 
collaborations and breakthroughs? How do we ensure a sustainable, vibrant, and dynamic bioinformatics community in Nigeria?

Conference aims and objectives: Why did we turn up in the city of Lagos?

In this article, we report on the First Nigerian Bioinformatics Conference (FNBC) 2019 (\#FNBC19), themed: "Bioinformatics in the era of Genomics in Africa", scheduled from 24th - 26th June, 2019, and hosted by the Nigerian Bioinformatics and Genomics Network (NBGN) (http://www.nbgnetwork.org) (REF) in collaboration with the Nigerian Institute of Medical Research (NIMR) (https://nimr.gov.ng), Lagos, Nigeria. The choice of the city of Lagos for FNBC19 was strategic and encompassing due to its cosmopolitan nature, flexible entrant routes (flight, road, and rail) by national, continental, and international participants, and NIMR was chosen due to its institutional and professional central nature, and its long history of contributions to genomics and bioinformatics in Nigeria. In order to provide an avenue to create a dynamic bioinformatics community in Nigeria, we turned up in the city of Lagos, Nigeria, with some specific aims and objectives for FNBC19: i) Provide a maiden discussion and congregation platform for all bioinformatics investigators in Nigeria; either investigating in Nigeria or outside Nigeria, ii) identify the scope of research and research areas involving the use of Bioinformatics and Genomics in Nigeria, iii) Establish research and professional connections or collaborations amongst, and within, identified research areas. This would also include establishing collaborations between government departments, national research institutes, academic institutions, and industries. iv) Engage the discussion for research strengthening and a continuous and regular congregation of the bioinformatics community in Nigeria.

Conference program of events: The planning, structure, and activities.

Time series leading up to the conference: The planning

Preparations leading up to FNBC19 commenced in March 2018. The preliminary set of members of the planning committee (steering committee, local organising committee, program committee) were assembled in June 2018 by which time proper preparations commenced and involved an average of one planning meeting per month between March - December, 2018, followed by an average of three planning meetings 
(adhoc meetings inclusive) per month between January - June, 2019. The planning stage involved conceptualization of the conference structure, fund sourcing to implement the conference strategies, establishment of the three sub-committees above, appointment of volunteers (6) into the various established committees, recruitment of six volunteers to drive various activities during the pre-conference and main conference, decision on various resources needed for the conferences, strategic financial accountability to ensure their timely procurement. This also involved the recruitment of six (6) volunteers nearer the time to FNBC19 (Figure S1). Up to 76 applications (Figure S1) were received for only 6 places, and selections were based on merits: Statements of motivations, recommendations, gender and geographical diversity of applicants. Conference advertisements were carried out via social media engagements on the NGBN social media accounts and mailing list, institutional and other bioinformatics network's mailing lists (e.g. $\underline{\mathrm{EB}}, \underline{\mathrm{H} 3 \mathrm{~A}}$ ), and oral engagements with heads of research Institutions, policy makers and renowned genomic / bioinformatics educationists within and outside Nigeria. For information on call for abstracts (oral and poster; abstract reviews and notifications), call for volunteers, call for travel fellowship awards, call for workshop applications, sources of funds, and other conference important dates please visit: http://www.ngbioinformaticsconference.com Confirmation of keynote and invited speakers and call for volunteers and notifications were also carried out before June 2019. All arrangements requiring local knowledge were carried out by the local organising committee.

The pre-conference workshops: Grant writing and Ensemble genome browser

The conference featured two pre-conference workshops which took place on 24th June, 2019, and tagged: "A practical guide to writing a grant proposal" and "Assessing Genomic Data using the Ensembl Genome Browser" (click to view conference program at a glance) respectively. The grant writing workshop was facilitated by Prof. Nicki Tiffin, University of Cape Town, South Africa, with an attendance of twenty (20) participants comprising primarily of $\mathrm{PhD}$ students and postdoctoral fellows (data not shown). The topics covered include: Sourcing for eligible and relevant grants, administrative and practical issues, and scientific structure of the grant proposal (introduction, aims, objectives, methods/activities, summary/abstract and budgeting). 
The workshop also entertained practical and feedback sessions involving grant writing group work case studies. The Ensembl Browser workshop was facilitated by Dr. Benjamin Moore, Ensembl Outreach Officer, European Bioinformatics Institute, Cambridge, United Kingdom, with 40 registered (and 10 unregistered) participants participants' being in attendance (Figure S2) and welcomed primarily post graduate students and research scientists (Figure S2a). Topics covered include; Introduction to Ensembl and the region in detail view, genes and transcript annotation, variation data and the VEP, regulatory data, comparative genomics and BioMart. The training materials can be accessed via this link: http://training.ensembl.org/events/2019/201906-24-FNBC. Selections for participations in both workshops (Ensembl and grant writing) were made based on participants potential to benefit the most from the workshops as well as advance this knowledge in their respective institutions or workplaces (Figure S2).

The actual conference events: Structure and activities

\section{Opening ceremony, presentations, and inauguration of NBGN}

The conference was adapted as per ASBCB conference guidelines (http://www.asbcb.org) (Adebamowo et al., 2018; De Villiers et al., 2011; Rafael et al., 2017; Ramdayal, et al., 2014). The conference started out in the morning of Tuesday, 25th June, 2019, in the following formats: Arrival of guests and delegates, national media teams, recognition of invited dignitaries, welcome address by the Host - Director General, NIMR: Prof. Babatunde Salako, who was represented by Deputy Director of Research (NIMR), Dr Oliver Ezechi, welcome address by the conference local organising committee, Dr Bamidele Iwalokun, welcome address by the conference chair, Dr Segun Fatumo, short speeches and good will messages from invited guests and dignitaries (Figure 1, and additional file in supplementary for a full description of events). This was preceded by welcome speeches from chairs of the local organising committee, invited dignitaries, and the President of NBGN, Dr Segun Fatumo. This was again followed by a keynote opening speech from Prof. Babatunde Salako, represented by Dr Oliver Ezechi, which focused on "Global trends in bioinformatics: The need to build capacity in Nigeria"' (see additional file in supplementary for all other keynotes, invited talks, oral and poster presentations). There was a total of 129 
presentations distributed across four presentation streams: Keynote speech (8), invited speech (6), oral presentation (25), and poster presentations (83) (Figure 2, 3) focusing mainly on genetic basis of diseases, databases and infrastructure, and agricultural applications. There were a total of 6 conference sessions, and each conference session followed the sequential format: one keynote speech, one invited talk, 5 oral presentations. A tea break and / or lunch break followed after each session to enhance networking.

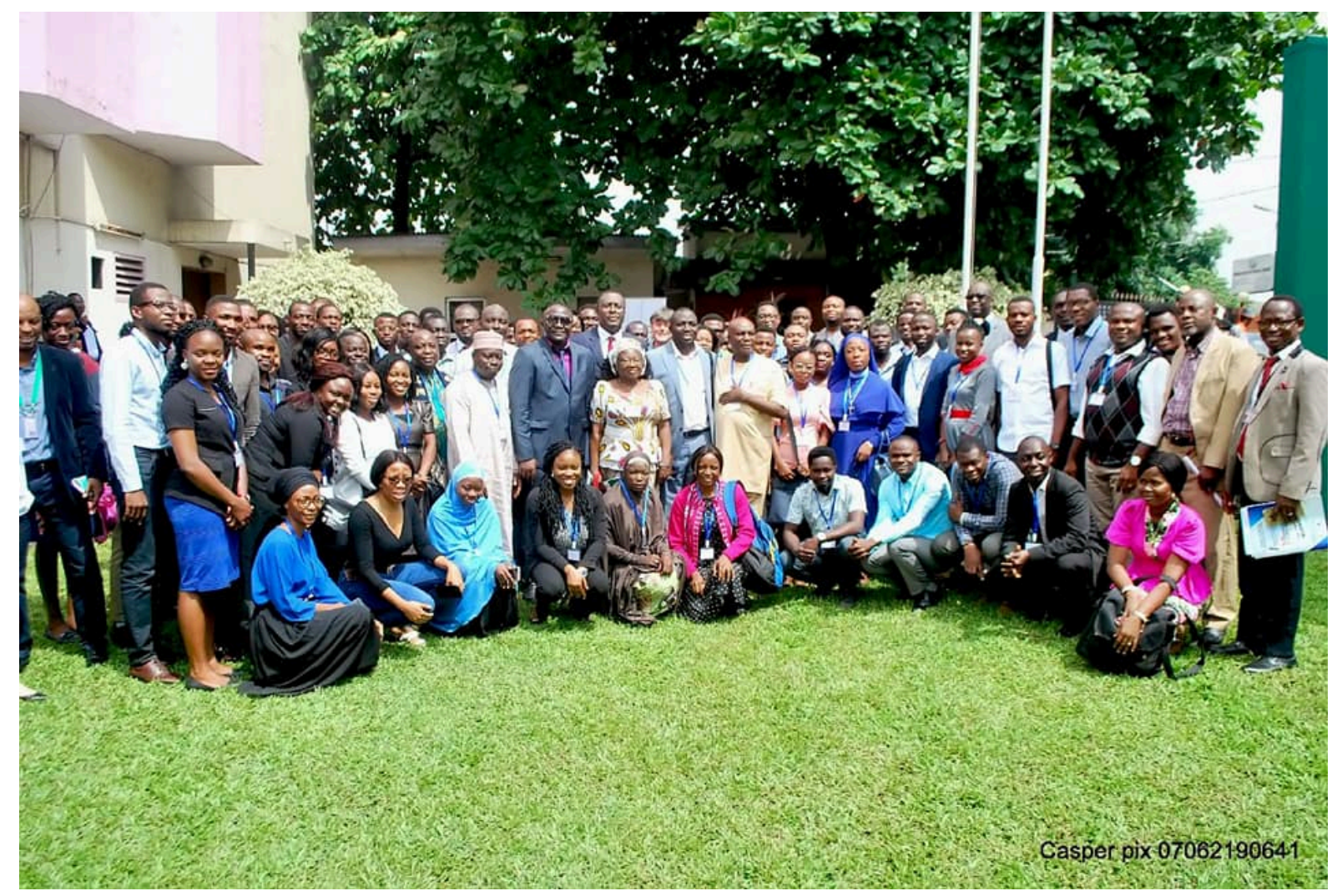

Figure 1. There are more bioinformatics interest groups in Nigeria than we imagined. The figure shows the FNBC conference group picture taken shortly after the opening ceremony with over 150 actual confirmed participants. Present in the figure are keynote speakers, invited guests, conference host (represented by the Deputy Director General of NIMR), volunteers, oral and poster presenters, and other conference participants from across Nigeria and up to 7 countries (see Figure 2 and 3). There were additional participants from host institutes and neighbouring institutes who attended the conference opening ceremony without prior notice and registration, so we estimate that the total number of combined participants could be up to 186 (see Figure 2). 
Conference keynote speakers include: Prof. Babatunde Salako, Prof. Nashiru Oyekanmi, Prof. Ezekiel Adebiyi, Prof. Adenike Osofisan, Prof. Christian Happi (represented by Dr Onikepe Folarin), Prof. Rapheal Isokpehi, and Prof. Mayowa Owolabi (represented by Dr Onoja Akpa). Conference invited speakers include: Prof. Ikemefuna Uzochukwu, Dr Andreas Gisel, Dr Voke Toye, and Dr Ben Moore. For extensive details on speech reports, all presentation topics, titles, contents, and conference schedules / timings, please see see additional file in supplementary). Each oral presentation was selected based on the recommendations of three teams of national and international reviewers who are experts in the field of bioinformatics and / or genomics. The poster abstracts were competitively selected for the conference by experts comprising 83 poster presentations. The posters were categorised into odd and even numbers for each respective conference days (see additional file in supplementary).

The inauguration ceremony of the Nigerian Bioinformatics and Genomics Network (NBGN) was observed on 26th June, 2019 (REF). This was chaired by Dr David Oladele and Dr. Bamidele Iwalokun followed by inauguration presentations from Dr Segun Fatumo and Dr ThankGod Ebenezer, and goodwill messages from the Genetics Society of Nigeria (GSN), the Biotechnology Society of Nigeria (BSN), the Nigerian Bioinformatics Research and Education Network (NBREN), and the Nigerian Society of Human Genetics. The inauguration of NBGN was concluded with the presentation of awards and special recognitions to Prof. Nashiru Oyekanmi and Prof Ezekiel Adebiyi for outstanding leadership and training in bioinformatics in Nigeria (REF). FNBC conference awards were also presented to: Nwuba Chiamaka, Abdusalam Toyin, and Ayorinde Afolayan for best oral presentation (1st, 2nd, and 3rd positions respectively), Temitope Ekundayo, Onyeka Chukwudozie, and Joyce Ayoola, for best poster presentations (1st, 2nd, and 3rd positions respectively), Faith Ogbole as the most dedicated conference volunteer, and Kolawole Oladipo as the most dedicated conference logistics personnel. The conference concluded with a group dinner by the members of the planning committee at Shoregate Hotels, Ikeja, Lagos.

Conference registration, attendance, travel fellowships, and volunteers 
The conference recorded a total of 195 online registrations (Figure 2). Out of these 195 online registrations, 179 had affiliations with a Nigerian institution, while 16 had affiliations with institutions in South Africa, Morocco, Ethiopia, United States, United Kingdom, Mali, and Sudan (Figure 2). The online conference registrations included 78 PhD students and $51 \mathrm{MSc}$ students making up to $40 \%$ and $30 \%$ of all online registered respectively (Figure 2). Finally, there were 127 registered participants who identified as male, and 68 who identified as female. The actual conference attendance was estimated at 186 (see Figure 2) as there participants who opted for onsite conference registrations, participants who registered online and could not attend the conference, and participants who opted for the opening ceremony only which did not require registration (Figure 3). A total of 52 travel fellowships were awarded from across over 10 institutions in Nigeria and outside Nigeria. 6 volunteers were selected after a competitive application process that recorded 76 applicants, and travel fellowships were also awarded to the selected volunteers. Volunteers worked from 1st June - 28th June, 2019, with tasks mainly focusing on conference administrative activities and setting up conference venues (Figure S1). Additional 17 volunteers helped out at the conference who were not part of the volunteers selected through the competitive process; these volunteers were not designated as the official conference volunteers (Figure 1). 
A

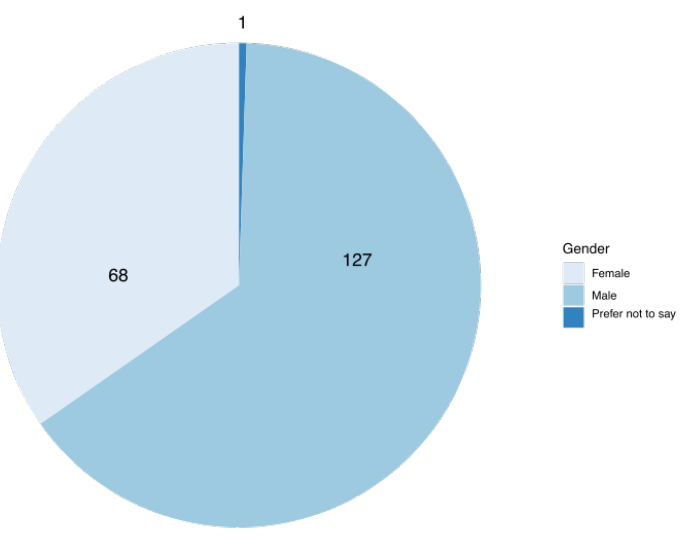

B

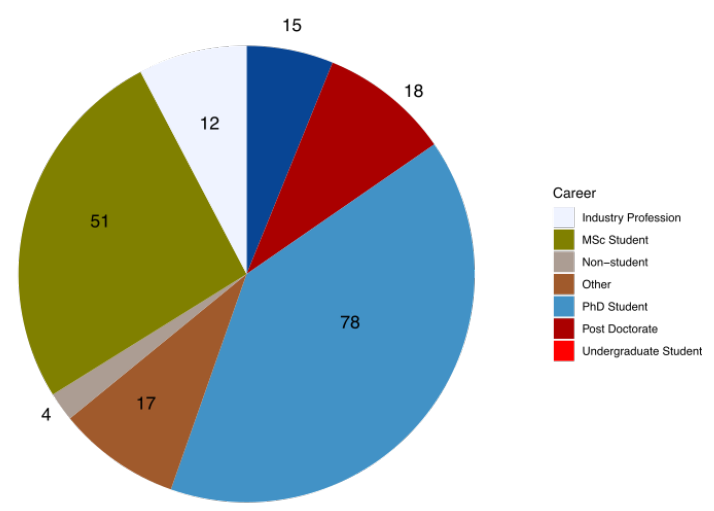

C

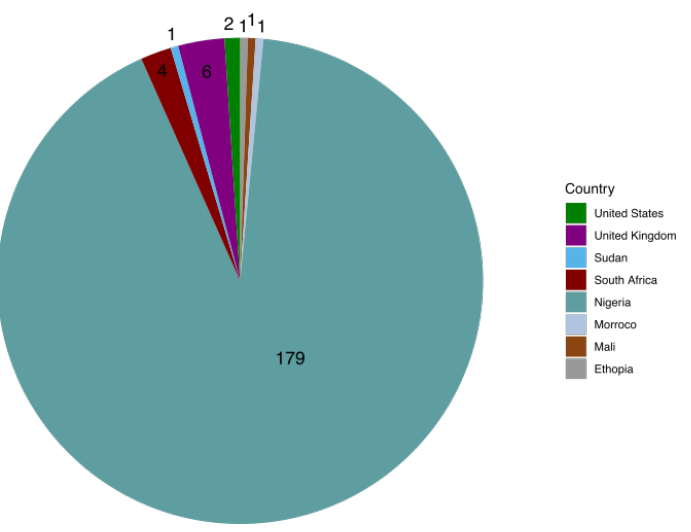

Figure 2. There is an uneven distribution of online registered participants across corresponding metric parameters. Panel $A$ shows pie charts shows a distribution across gender, with legends highlighted as male, female, or prefer not to say, with respective legend colours. The number of Female (68) attendees are half the corresponding number of male (127) attendees. Panel $B$ shows a pie chart distribution across various career stages with corresponding legend colours: Post Doctorate, PhD students, MSc students, undergraduates, non students, industry professions, and others. More participants identified as either PhD students (78) or MSc students (51). Panel C shows the pie chart distribution across countries of affiliations with corresponding legend colours: Ethiopia, Mali, Morocco, Nigeria, South Africa, Sudan, United Kingdom, and the United States. Participants affiliated with institutions in Nigeria (179) recorded more participations. Out of 194 online registered participants, 69 confirmed their registration by way of conference payments while 126 elected to pay onsite during online registration. To confirm actual conference participations, we printed 150 name tags based on conference online registration and estimated attendance: 91 of these name tags were claimed at the conference, while 59 name tags were unclaimed. 15 participants registered on-site without prior online registration, and up to 65 members of the NIMR staff community and surrounding academic institutes participated (especially the conference opening ceremony) without prior registration. There were 15 media / press personnels at the conference. Based on this analysis we estimate that the actual conference attendance is up to 186. 


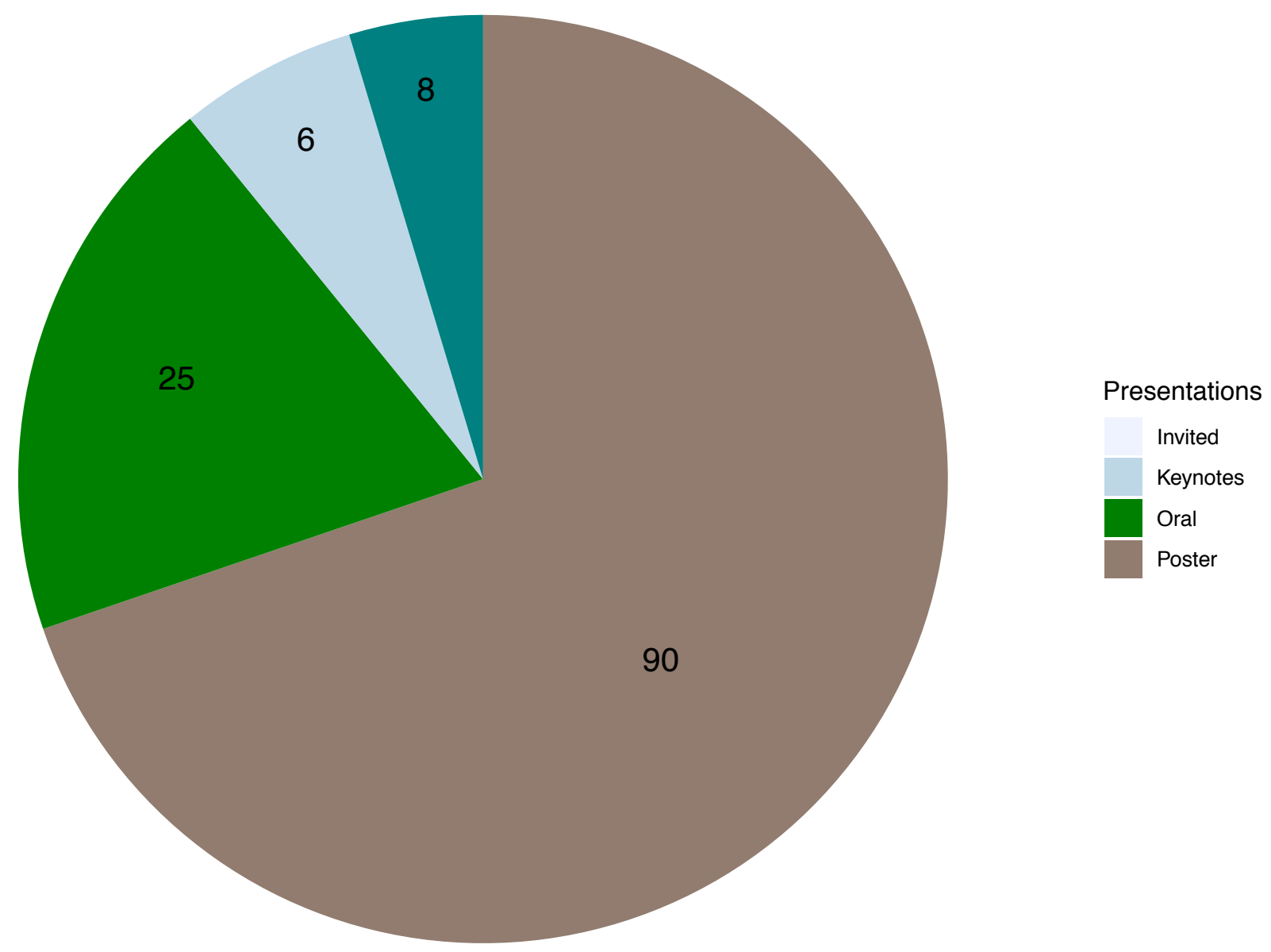

Figure 3. There was a wide range of presentations across varying professional stages. The pie charts shows the number of confirmed presentations for FNBC19 with corresponding colour legends: Keynotes (8), invited (6), oral (25), and poster (90). The keynote and invited speakers were made up of only professors and senior investigators in bioinformatics, genomics, or computer science. Oral and poster presenters were made up of mainly PhD students, and a few number of MSc students and undergraduates.

\section{Significance of the conference: Pathway to a new era}

Increased visibility for the Nigerian bioinformatics community: This conference brought to light the variable and wider research specialisations for the Nigerian bioinformatics community. For instance, Keynotes, invited guests, oral and poster presenters highlighted a wider variety of interesting current bioinformatics research topics (see additional file in supplementary for full abstracts, and click to view oral and poster presentation abstract titles); which was engaging and deepened conference 
participations. On the whole, the conference received a noticeable amount of participations from attendees outside Lagos (and Nigeria). Out of the 186 participants at the conference, up to 100 participants travelled from outside Lagos and Nigeria. There was a broad scope of research interests which included, amongst others, genomics, bioinformatics, microbiology, and biochemistry. This conference enabled an increase in the interconnectedness of several bioinformatics research groups in Nigeria and further increased collaborations amongst these research groups. For instance, during the conference, Prof. Oyekanmi Nash indicated interest to host the next bioinformatics conference in Abuja and further contribute to the course of NBGN. The conference also created bioinformatics awareness for persons outside the bioinformatics knowledge space; this is evident via social media advertisements and engagements, websites, scientific articles, Vanguard News (print media), Pharma News online, and national television outlets' commentators on TVC, Lagos Television (LTV), National Television Authority (NTA), Channels Television, and Silverbird Television (STV) (see weblink 1 in supplementary). There national media outlets repeated the conference news at varying intervals to ensure wider dissemination of information.

Nigeria positions as a vibrant community player within the African bioinformatics space: The conference attracted 16 participants from outside Nigeria out of 195 registered participants (Figure 1,2). This is encouraging considering it's a maiden conference. This conference ensured an increased connection between the Nigerian bioinformatics community and the continental / intercontinental bioinformatics community. This conference is also relevant to other African nations with emerging (or established) bioinformatics community wanting to either bring the bioinformatics community together or organise a maiden bioinformatics conference. For instance, with the first publication of the state of bioinformatics and computational in Nigeria (Fatumo, et al., 2014, ) several other African countries (e.g. South Africa, Ghana, and Zimbabwe) have taken up the challenge to report the state of bioinformatics and computational biology in their own countries (De Villiers, et al., 2015, Mulder, et al., 2016, Shoko, et al., 2018). 
Pathway to national impact: One unique characteristic of the conference was the presence of both scientists and non-scientists as well as officials of various government institutes and parastatals. This arrangement allowed for a penetration of bioinformatics awareness into the governmental and non-governmental space. This, in the future, will pave the way for increased, or seamless, support from the Nigerian government - particularly since the potential impact and significance of the field of bioinformatics (health, agriculture, and environment) were hugely highlighted in several talks during the conference sparking huge interests.

\section{Opportunities, lessons learned, and way forward}

The green landscape and opportunities: When the planning of the conference was initiated in March 2018, there were lack of awareness and understanding regarding opportunities that a congregational platform of Nigerian researchers in Genomics and Bioinformatics across several biomedicine, life science, agriculture, will generate. The extent to which key stakeholders in research and development space in Nigeria will embrace the maiden FNBC19 conference was also not known. We did not envisage the extent of the opportunities that abound within bioinformatics in Nigeria. Similarly, we did not realise how conference stakeholders (see acknowledgement section of this article) will embrace the conference. And finally, we also did not realise the sheer number of groups engaged in bioinformatics in Nigeria, many of whom possibly not so well known, or have sprung up over the last couple of years. For instance, we initially planned to host up to 60 participants at the conference, and we ended up having an estimated 186 actual participants (see Figure 2). When we put out a call for Ensembl conference workshop, we received 120 applications for only 35 places. Similarly, when we also put out a call for volunteering opportunities (with full travel fellowship award), we received 76 applications for only 6 places. The opportunities that abound are not only restricted to the population strength, they are also experienced in the green landscape that Nigeria presents for bioinformatics as well as increased emerging footprints for bioinformatics, which will make future bioinformatics practise and conferences easier in Nigeria.

Challenges and lessons learned: What could be done better? When we started to plan for FNBC19 in March 2018, we did not have a confirmed budget - this means we had 
no funding to run any aspect of the conference, including the conference preparation steps. In fact, we planned the conference on zero budget until in April / May 2019 when we received confirmation of sponsorships (see acknowledgement section of this article). This also means that the majority of the activities leading up to the conference were primarily driven by volunteerism on the part of the members of the planning committee. Amongst others, this volunteerism include: Website development, national and international phone calls, conference coordination logistics and transport, public engagement poster designs, conference data and information management, advertisements, and administrative tasks. There were additional challenges faced during the conference which was as a result of last-minute arrangements that led to pressures on the planning committee. For instance, the lunch logistics was somewhat cumbersome - this is because the conference cafeteria was in a different building from the conference auditorium and involved about 5 minutes walk with very limited resources and coordination available for mobility. The timing for the meals ran somewhat late due to delays in lunch preparation, as well as the transit time from the cafeteria to the main conference auditorium. This resulted in delays for sessions scheduled post-lunch; what this means is that, generally, all the afternoon sessions took longer than we had expected. There were some technical challenges faced during the conference, for example, the projector and microphones being faulty or not working effectively, the Wi-Fi bandwidth was not strong enough and intermittent power outages caused delays during respective sessions. There was a heavy reliance on volunteers and local organising committees for on-site conference logistics; mainly due to the assigned workload with minimal resources. The effect of this was experienced by some members of the planning committee which includes: Missing out on some of the conference aspects and weariness. Two oral presenters and one invited speaker were also absent at the conference without prior notifications to the conference planning committee thereby briefly interrupting the sequence of presentations. Finally, as previously mentioned, considering that we did not expect the sheer number of interests and participations, we had to make specific logistical arrangements to accommodate some last-minute non envisage scenarios, these include logistics for registration materials, catering services, pre-conference workshop venues, and poster presentation venue. 
Conclusions, recommendations and way forward: FNBC19 did achieve its aim of bringing the Nigerian bioinformatics community together to enhance collaborations and drive further research activities; overall, FNBC19 was a success. Success measuring parameters for FNBC19 include: 1) collaborations between senior scientists, 2) collaborations between students and senior scientists, 3) collaborations amongst students / collaborations between students and students, 4) inauguration of NBGN (REF), and 5) bioinformatics awareness creation in Nigeria. Of particular note is the collaborations between senior scientists and students. For example, considering that $\mathrm{PhD}$ and MSc students made up the larger proportion (over $50 \%$ ) of the conference participations, this was very encouraging, and created synergy and partnerships of engagement between senior scientists and students. We recommend this kind of conference engagements in future bioinformatics conferences in Nigeria, especially maiden conferences; the next conference will be scheduled by the NBGN leadership team. Other recommendations, and outcomes from the post-conference round off meeting, for future bioinformatics conferences that should be organised by NBGN include:

- Hosting rights and responsibilities should be requested and defined well ahead of any conference. This should include a signed Memorandum of Understanding (MoU) between NBGN and any potential host.

- $\quad$ There is need to engage event planners to reduce pressures on local organising committee, and other local volunteers.

- There is a need to identify additional sponsorship streams to better fund more participants, especially students, to attend the conference.

- The conference abstract review mainly focused on human-health abstract review approach; there is a need to consider other areas of bioinformatics research specializations (e.g. agriculture; plants, animals, microbes, databases and infrastructure) in selecting reviewers for oral and poster presentations, and keynotes / invited talks.

- Submitted abstracts should be assigned early enough to selected experts, this will provide sufficient time for reviews and feedback.

- Conference hosting metrics should be developed for the selection of conference hosts and venues. Supportive hosts with effective and efficient 
logistical support, alongside other metrics items, should be identified and engaged.

- Individuals and personnel who will be committed to the demanding tasks of the conference should be identified either from the poll of existing members of the planning committee or elsewhere.

\section{Acknowledgements}

We are grateful to the steering committee, local organizing committee, program committee, and everyone who was involved in the organization of the conference and those who volunteered their time, resources and efforts for the success of the First Nigerian Bioinformatics Conference. In addition, we would like to acknowledge and thank our funding sources: Nigerian Bioinformatics and Genomics Network (NBGN), The African Partnership for Chronic Diseases Research (APCDR), Centre for Genomics Research and Innovation/National Biotechnology Development Agency (CGRI/NABDA), Covenant University Bioinformatics Research (CUBRe), The European Bioinformatics Institute (EMBL-EBI), Human Heredity and Health in Africa (H3Africa) Bioinformatics Network (H3ABioNet) and the supportive host - the Nigerian Institute of Medical Research (NIMR). The workshops were made possible by generous support from the following; Nigerian Institute of Medical Research (NIMR), European Bioinformatics Institute (EBI), Covenant University Bioinformatics Research (CUBRe), Center for Genomic Research and Innovation (CGRI), African Partnership for Chronic Disease Research (APCDR), and the Nigerian Bioinformatics and Genomics Network (NBGN).

We would like to thank our keynote speakers - Prof. Babatunde L. Salako, Prof. Nicki Tiffin, Prof. Raphael Isokpehi, Prof Adenike Osofisan, Prof. Oyekanmi Nash, Prof. Ezekiel Adebiyi, Prof. Christian Happi, Prof Mayowa Owolabi; and the invited speakers - Dr. Olaposi Idowu Omotuyi, Dr. Ben Moore, Dr. Voke Toye, Prof. Lawrence Okoror, Dr. Andreas Gisel and Prof. Ikemefuna Uzochukwu, for agreeing to share their knowledge with the conference audience.

We are grateful to Landmark University Omu-Aran volunteering team for their contributions during the conference: Arowolo Michael Olaoluwa, Ogundokun Roseline 
Oluwaseun, Adeniyi Emmanuel Abidemi, Olawepo Samuel Oladayo, Ayegba Peace, Ayoola Joyce Adebusola, Omosebi Oluwatosin Adejoke, Aladeitan Benedicta Boluwaji; last and not the least on this list is Temitope Ogungbesan from CUBRe and Jamilu Bello from Fountain University, Osogbo. We are especially grateful to FNBC19 oral and poster presenters as well as participants who graced the event. Finally, we are grateful to Mr. M. I. Ezerendu for helping to coordinate dissemination of information during and after the conference by liaising with the various media outlets mentioned in this article.

\section{Authors contributions}

Conceived conference: Segun Fatumo

Conference conveners: ThankGod Ebenezer, Chinwe Ekenna, Segun Fatumo*

Sourced for conference funds: Chinwe Ekenna*, Segun Fatumo

Conference public engagement: ThankGod Ebenezer ${ }^{\star \downarrow}$, Segun Fatumo, Olaitan Awe ${ }^{\star \downarrow}$, Olugbenga Oluwagbemi

Reviewed conference abstracts^: Tijjani Fatai, Victor Osamor, Chinwe Ekenna, ThankGod Ebenezer, Segun Fatumo, Chika Onwuamah*

Designed conference website: Olaitan Awe

Reviewed conference website: ThankGod Ebenezer, Segun Fatumo, Olaitan Awe*

Conference volunteers: Faith Ogbole, Benjamin Benthai, ljeoma Asilebo, Abati abraham, Tawakalt Oduwole, Emmanuel Adamolekun

Logistics for conference funding applications and other logistics: Deborah E. Fasesan, Zainab Kashim, Nusrah Afolabi Balogun.

Drafted conference schedule and booklet: ThankGod Ebenezer, Segun Fatumo*, Elijah Kolawole Oladipo*

Reviewed conference booklet: ThankGod Ebenezer, Segun Fatumo, Elijah Kolawole Oladipo, Olugbenga Oluwagbemi

Conference local organisers: Idowu A. Taiwo ${ }^{\ddagger}$, Jelili Oyelade, Bamidele Iwalokun ${ }^{\star \downarrow}$

Pre-conference workshop shortlist and organisations: ThankGod Ebenezer, Segun Fatumo, Itunu Iseoluwa* ${ }^{\star}$, Callistus Akinyele ${ }^{\star \downarrow}$

Drafted manuscript: ThankGod Ebenezer ${ }^{\star}$, Segun Fatumo, Elijah Kolawole Oladipo, Jelili Oyelade, Marion Adebiyi, Itunuoluwa Isewon, Yvonne Ajamma, Olaitan Awe, Voke Toye, Charles Oluwaseun Adetunji, Umar Ahmad

Reviewed manuscript: ThankGod Ebenezer ${ }^{\star}$, Segun Fatumo, Bamidele Iwalokun, Nashiru Oyekanmi, Yvonne Ajamma 


\section{Authors' contributions legends}

*Indicates lead personnel

*ndicates major contributor/s

${ }^{\wedge}$ We acknowledge other conference abstract reviewers

Where no symbol exists in the authors' contribution category, it is believed that authors contributed equally in the contribution category.

\section{Supplementary}

Figures

A

B
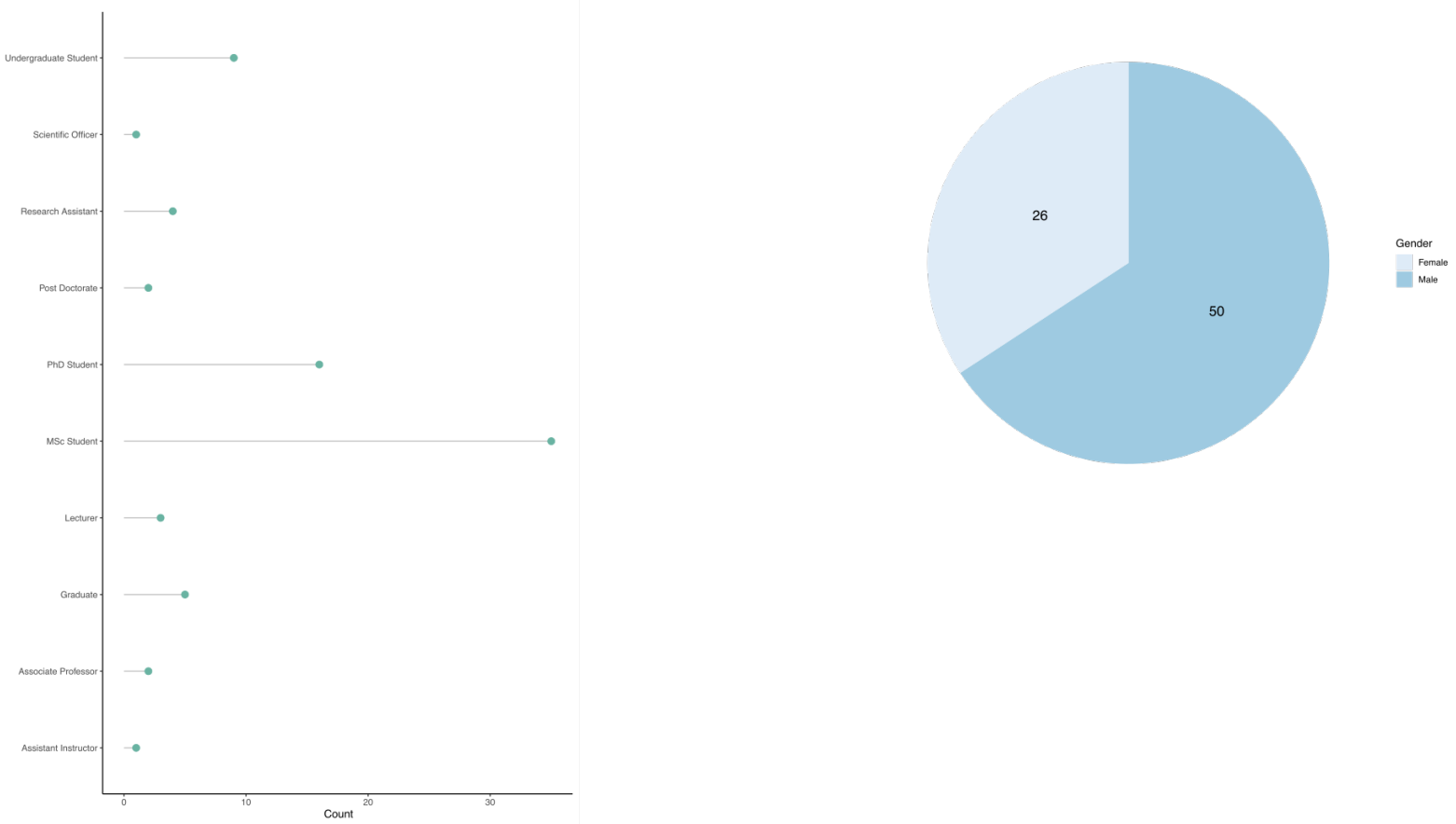

Figure S1. There is a high level of volunteering interest for only six available places. Panel $A$ is a lolliplot showing the career stage distribution of 76 submitted applications for FNBC19 conference volunteer call. MSc and PhD students made up the majority number of applicants (> $50 \%$ ). Y-axis represents the career stages of applicants, and X-axis represent the count value. Coloured node shows the endpoint of count for each respective career stage. Panel B is a pie chart showing the gender distribution of 76 submitted applications for FNBC19 conference volunteer call. There are more applications from male genders in comparison to female genders. 
A

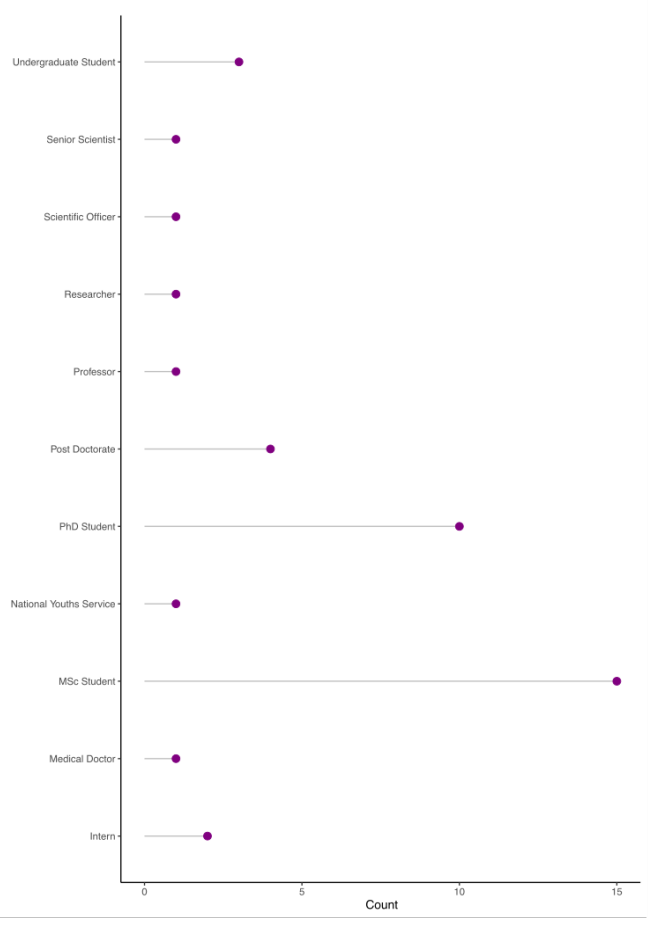

B

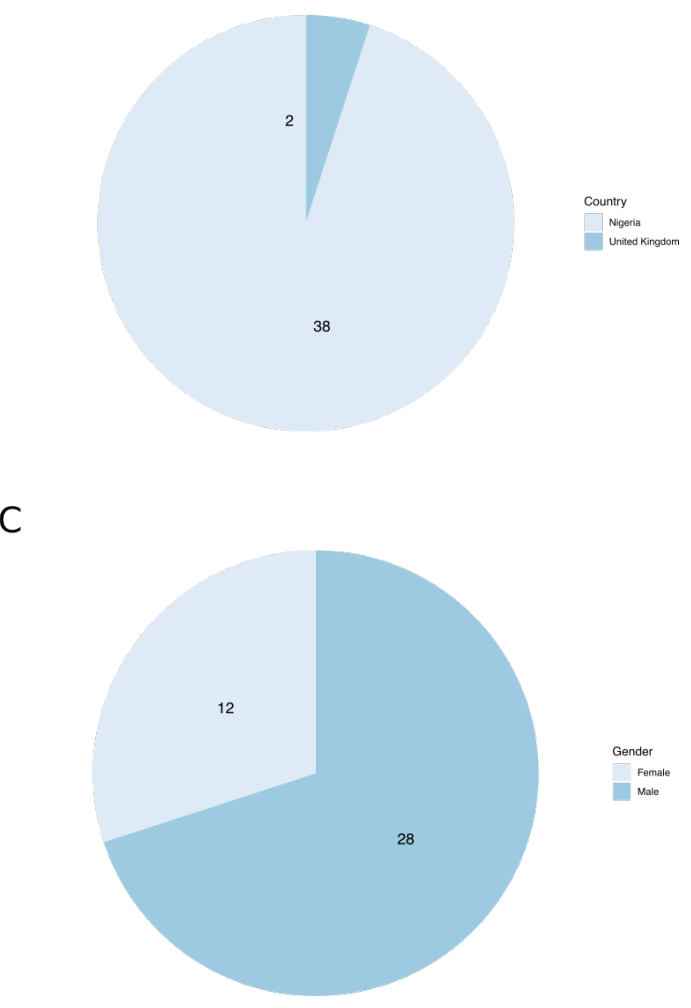

Figure S2. The number of workshop participants are varies across career and gender for FNBC19 pre-conference Ensembl Genome Browser workshop. Panel A is a lolliplot showing the the career stages of 40 online registered participants for FNBC19 pre-conference workshop (Ensembl Genome Browser). MSc and PhD students made up the majority number of applicants (>50\%). Y-axis represents the career stages of applicants, and $X$-axis represent the count value. Coloured node shows the endpoint of count for each respective career stage. Panel B is a pie chart shows the country distribution of 40 online registered participants for FNBC19 pre-conference workshop (Ensembl Genome Browser). There is no significant country representation or affiliations for FNBC19 preconference workshop. Panel $\mathrm{C}$ is a pie chart showing the gender distribution for FNBC19 preconference workshop (Ensembl Genome Browser).

Additional file

Link to the conference comprehensive program of events:

(https://drive.google.com/file/d/18euoKTlunNBq8n1aPCmby6SS9aUPPgnM/view?usp=shari ng)

Weblink

Weblink 1. Link to the conference news / media video file: https://youtu.be/6-KkOJWEdNM 


\section{References}

Adebamowo, S. N., Francis, V., Tambo, E., Diallo, S. H., Landouré, G., Nembaware, V., ... Ngomi, N. (2018). Implementation of genomics research in Africa: challenges and recommendations. Global Health Action, 11(1), 1419033. https://doi.org/10.1080/16549716.2017.1419033

Adeyemo, A. A., Amodu, O. K., Ekure, E. E., \& Omotade, O. O. (2018). Medical genetics and genomic medicine in Nigeria. Molecular Genetics \& Genomic Medicine, 6(3), 314-321. https://doi.org/10.1002/mgg3.419

Azeez, B., Mossey, P., Tiffin, N., Adeyemo, W., Eshete, M., Chrispinanus, M., ... Adebowale, A. (2015). Multidisciplinary approach to genomics research in Africa: the AfriCRAN model. Pan African Medical Journal, 21. https://doi.org/10.11604/pamj.2015.21.229.7380

Bah, S. Y., Morang'a, C. M., Kengne-Ouafo, J. A., Amenga-Etego, L., \& Awandare, G. A. (2018). Highlights on the Application of Genomics and Bioinformatics in the Fight Against Infectious Diseases: Challenges and Opportunities in Africa. Frontiers in Genetics, 9, 575. https://doi.org/10.3389/fgene.2018.00575

Berg, P. (2006). Origins of the human genome project: why sequence the human genome when $96 \%$ of it is junk? American Journal of Human Genetics, 79(4), 603-605. https://doi.org/10.1086/507688

C. elegans Sequencing Consortium, T. C. elegans S. (1998). Genome sequence of the nematode $C$. elegans: a platform for investigating biology. Science (New York, N.Y.),282(5396), 2012-2018.

https://doi.org/10.1126/science.282.5396.2012

Dahm, R. (2005). Friedrich Miescher and the discovery of DNA. Developmental Biology, 278(2), 274-288. https://doi.org/10.1016/J.YDBIO.2004.11.028

DeLisi, C. (2008). Santa Fe 1986: Human genome baby-steps. Nature, 455(7215), 876-877. https://doi.org/10.1038/455876a

Fatumo, S. A., Adoga, M. P., Ojo, O. O., Oluwagbemi, O., Adeoye, T., Ewejobi, I., ... Nashiru, O. (2014). Computational biology and bioinformatics in Nigeria. PLoS Computational Biology, 10(4), e1003516. https://doi.org/10.1371/journal.pcbi.1003516

Folarin, O. A., Ehichioya, D., Schaffner, S. F., Winnicki, S. M., Wohl, S., Eromon, P., ... Happi, C. T. (2016). Ebola Virus Epidemiology and Evolution in Nigeria. Journal of Infectious Diseases, 214(suppl 3), S102-S109. https://doi.org/10.1093/infdis/jiw190

Gauthier, J., Vincent, A. T., Charette, S. J., \& Derome, N. (2018). A brief history of bioinformatics. Briefings in Bioinformatics. https://doi.org/10.1093/bib/bby063 
Goffeau, A., Barrell, B. G., Bussey, H., Davis, R. W., Dujon, B., Feldmann, H., ... Oliver, S. G. (1996). Life with 6000 Genes. Science, 274(5287), 546-567. https://doi.org/10.1126/science.274.5287.546

H3Africa Consortium, T. H., Rotimi, C., Abayomi, A., Abimiku, A., Adabayeri, V. M., Adebamowo, C., ... Zar, H. (2014). Research capacity. Enabling the genomic revolution in Africa. Science (New York, N.Y.), 344(6190), 13461348. https://doi.org/10.1126/science.1251546

Hagen, J. B. (2000). The origins of bioinformatics. Nature Reviews Genetics, 1(3), 231-236. https://doi.org/10.1038/35042090

International Human Genome Sequencing Consortium. (2004). Finishing the euchromatic sequence of the human genome. Nature, 431(7011), 931-945. https://doi.org/10.1038/nature03001

Jean-Baka Domelevo Entfellner. (2018). Building a bioinformatics community for agricultural sciences in Africa.

Karikari, T. K. (2015). Bioinformatics in Africa: The Rise of Ghana? PLOS Computational Biology, 11(9), e1004308. https://doi.org/10.1371/journal.pcbi.1004308

Karikari, T. K., Quansah, E., \& Mohamed, W. M. Y. (2015). Developing expertise in bioinformatics for biomedical research in Africa. Applied \& Translational Genomics, 6, 31-34. https://doi.org/10.1016/J.ATG.2015.10.002

Leder, P., \& Nirenberg, M. (1964). RNA CODEWORDS AND PROTEIN SYNTHESIS, II. NUCLEOTIDE SEQUENCE OF A VALINE RNA CODEWORD. Proceedings of the National Academy of Sciences of the United States of America, 52(2), 420. https://doi.org/10.1073/PNAS.52.2.420

Leslie A. Pray. (2008). Discovery of DNA Double Helix: Watson and Crick I Learn Science at Scitable. Nature Education, 1(1), 100. Retrieved from https://www.nature.com/scitable/topicpage/discovery-of-dna-structure-andfunction-watson-397/

Lewin, H. A., Robinson, G. E., Kress, W. J., Baker, W. J., Coddington, J., Crandall, K. A., ... Zhang, G. (2018). Earth BioGenome Project: Sequencing life for the future of life. Proceedings of the National Academy of Sciences of the United States of America, 115(17), 4325-4333.

https://doi.org/10.1073/pnas.1720115115

Making, I. of M. (US) C. to S. D., \& Hanna, K. E. (1991). The Human Genome Project: The Formation of Federal Policies in the United States, 1986-1990. Retrieved from https://www.ncbi.nlm.nih.gov/books/NBK234203/

Mulder, N., Adebamowo, C. A., Adebamowo, S. N., Adebayo, O., Adeleye, O., Alibi, M., ... Souiai, O. (2017). Genomic Research Data Generation, Analysis and Sharing - Challenges in the African Setting. Data Science Journal, 16(0). https://doi.org/10.5334/dsj-2017-049 
Mulder, N., Adebamowo, C. A., Adebamowo, S. N., Adebayo, O., Adeleye, O., Alibi, M., ... Souiai, O. (2017). Genomic Research Data Generation, Analysis and Sharing - Challenges in the African Setting. Data Science Journal, 16(0). https://doi.org/10.5334/dsj-2017-049

Mulder, N. J., Adebiyi, E., Adebiyi, M., Adeyemi, S., Ahmed, A., Ahmed, R., ... consortium, as members of the H. (2017). Development of Bioinformatics Infrastructure for Genomics Research. Global Heart, 12(2), 91-98. https://doi.org/10.1016/j.gheart.2017.01.005

Mulder, N. J., Adebiyi, E., Alami, R., Benkahla, A., Brandful, J., Doumbia, S., ... H3ABioNet Consortium, T. H. (2016). H3ABioNet, a sustainable pan-African bioinformatics network for human heredity and health in Africa. Genome Research, 26(2), 271-277. https://doi.org/10.1101/gr.196295.115

Munung, N. S., Mayosi, B. M., \& de Vries, J. (2018). Genomics research in Africa and its impact on global health: insights from African researchers. Global Health, Epidemiology and Genomics, 3, e12. https://doi.org/10.1017/gheg.2018.3

NIRENBERG, M. W., \& MATTHAEI, J. H. (1961). The dependence of cell-free protein synthesis in E. coli upon naturally occurring or synthetic polyribonucleotides. Proceedings of the National Academy of Sciences of the United States of America, 47(10), 1588-1602. https://doi.org/10.1073/pnas.47.10.1588

Oloniniyi, O. K., Unigwe, U. S., Okada, S., Kimura, M., Koyano, S., Miyazaki, Y., ... Yasuda, J. (2018). Genetic characterization of Lassa virus strains isolated from 2012 to 2016 in southeastern Nigeria. PLOS Neglected Tropical Diseases, 12(11), e0006971. https://doi.org/10.1371/journal.pntd.0006971

Ramsay, M., \& Sankoh, O. (2016). African partnerships through the H3Africa Consortium bring a genomic dimension to longitudinal population studies on the continent. International Journal of Epidemiology, 45(2), 305-308. https://doi.org/10.1093/ije/dyv187

Shaffer, J. G., Mather, F. J., Wele, M., Li, J., Tangara, C. O., Kassogue, Y., ... Doumbia, S. O. (2019). Expanding Research Capacity in Sub-Saharan Africa Through Informatics, Bioinformatics, and Data Science Training Programs in Mali. Frontiers in Genetics, 10, 331. https://doi.org/10.3389/fgene.2019.00331

Shoko, R., Manasa, J., Maphosa, M., Mbanga, J., Mudziwapasi, R., Nembaware, V., ... Patterton, H. (2018). Strategies and opportunities for promoting bioinformatics in Zimbabwe. PLoS Computational Biology, 14(11), e1006480. https://doi.org/10.1371/journal.pcbi.1006480

Tan, S. C., \& Yiap, B. C. (2009). DNA, RNA, and protein extraction: The past and the present. Journal of Biomedicine and Biotechnology, Vol. 2009, p. 574398. https://doi.org/10.1155/2009/574398 
Watson, J. D., \& Cook-Deegan, R. M. (1991). Origins of the Human Genome Project. FASEB Journal: Official Publication of the Federation of American Societies for Experimental Biology, 5(1), 8-11. https://doi.org/10.1096/fasebj.5.1.1991595

WATSON, J. D., \& CRICK, F. H. C. (1953). Molecular Structure of Nucleic Acids: A Structure for Deoxyribose Nucleic Acid. Nature, 171(4356), 737-738. https://doi.org/10.1038/171737a0

Weissenbach, J. (2016). The rise of genomics. Comptes Rendus Biologies, 339(78), 231-239. https://doi.org/10.1016/J.CRVI.2016.05.002 